\title{
A Criterion for Estimating the Strength of Flocculated Aggregates in Salt Solutions
}

\author{
Matías Jeldres ${ }^{1}$, Luis Ayala ${ }^{2}$, Pedro Robles ${ }^{3}$ (D) Edelmira Gálvez ${ }^{4}$, Williams H. Leiva ${ }^{5}$, Pedro G. Toledo ${ }^{6}(\mathbb{D}$ \\ and Ricardo I. Jeldres $1, *$ (D) \\ 1 Departamento de Ingeniería Química y Procesos de Minerales, Facultad de Ingeniería, \\ Universidad de Antofagasta, Antofagasta 1240000, Chile; hugo.jeldres.valenzuela@ua.cl \\ 2 Faculty of Engineering and Architecture, Universidad Arturo Prat, Almirante Juan José Latorre 2901, \\ Antofagasta 1240000, Chile; luisayala01@unap.cl \\ 3 Escuela de Ingeniería Química, Pontificia Universidad Católica de Valparaíso, Valparaíso 2340000, Chile; \\ pedro.robles@pucv.cl \\ 4 Department of Metallurgical and Mining Engineering, Universidad Católica del Norte, \\ Avenida Angamos 0610, Antofagasta 1270709, Chile; egalvez@ucn.cl \\ 5 RheoMining Ingeniería y Proyectos SPA, Avenida Angamos 1161, Antofagasta 1240000, Chile; \\ williams.leiva@rheomining.cl \\ 6 Chemical Engineering Department and Surface Analysis Laboratory (ASIF), Universidad de Concepcion, \\ P.O. Box 160-C, Correo 3, Concepcion 4030000, Chile; petoledo@udec.cl \\ * Correspondence: ricardo.jeldres@uantof.cl
}

check for updates

Citation: Jeldres, M.; Ayala, L.; Robles, P.; Gálvez, E.; Leiva, W.H.; Toledo, P.G.; Jeldres, R.I. A Criterion for Estimating the Strength of Flocculated Aggregates in Salt Solutions. Minerals 2021, 11, 713. https://doi.org/10.3390/min11070713

Academic Editor: Mercedes Suárez

Received: 28 April 2021

Accepted: 26 June 2021

Published: 1 July 2021

Publisher's Note: MDPI stays neutral with regard to jurisdictional claims in published maps and institutional affiliations.

Copyright: (c) 2021 by the authors. Licensee MDPI, Basel, Switzerland. This article is an open access article distributed under the terms and conditions of the Creative Commons Attribution (CC BY) license (https:// creativecommons.org/licenses/by/ $4.0 /)$.
Abstract: A simple criterion is proposed to quantitatively estimate the resistance of aggregates based on incremental mechanical shear disturbances. Aggregate strength can be affected by the hydrodynamic conditions under which flocculation occurs; therefore, an experimental method is standardized to determine the resistance of aggregate structures that are formed under defined conditions of salinity $(\mathrm{NaCl} 0-0.1 \mathrm{M})$, mixing time $(3 \mathrm{~min})$, and mean shear rate $\left(\mathrm{G}=273 \mathrm{~s}^{-1}\right)$. Kaolin particles were flocculated in saline solutions with an anionic flocculant of high molecular weight. The method involves increasing the mean shear rate $\left(G=0-1516 \mathrm{~s}^{-1}\right)$. Each increment represents a new experiment that starts from the base of $273 \mathrm{~s}^{-1}$. Target aggregates are increasingly fragmented as mechanical disturbance increases. The monotonic relationship between the mean shear rate increments $(\Delta \mathrm{G})$ and the final size of the aggregates is used for a quantitative estimate of the resistance of the target aggregates since this resistance underlies this relationship. The evolution of aggregate size is analyzed by the Focused Beam Reflectance Measurement (FBRM) method, which may capture the chord length distribution on concentrated slurries. To estimate and compare the resistance of the target aggregates in solutions with different salinities, a pseudo-first-order model that describes the rupture degree as a function of shear rate increments obtains the characteristic shear rate. The rupture percentage is reached with considerably lower agitation increments at higher salinity than at low salinity. This criterion is expected to help improve the efficiency of solid-liquid separation processes, especially in plants operating with seawater, be it raw or partially desalinated.

Keywords: kaolin flocculation; aggregate strength; salinity; flocculation kinetic; flocculation mechanism

\section{Introduction}

Particle flocculation is widely used in solid-liquid separation processes. The particles of a suspension form aggregates or flocs that settle due to gravity, accelerating the separation of a liquid phase and a solid-rich phase. The aggregation mechanism critically depends on the type of flocculant used. Flocculation can occur by neutralizing charges, electrostatic patches, or polymeric bridges [1-3]. This last type of flocculation is of great practical importance because numerous particles can simultaneously bind to the flocculant chains, which must be long enough for this purpose, forming massive aggregates that easily sediment. Vajihinejad et al. [4] have suggested that the length of the chain must exceed at 
least twice the thickness of the electrical double layer of the solid particles. The patch model is based on the formation of cationic sites or "patches" of cationic polyelectrolyte on the negative surface of the particles; in this way, aggregation occurs by electrostatic attraction between particles with and without patches. Charge neutralization aggregation occurs due to the reduction of repulsive forces between particles, allowing them to aggregate due to van der Waals attractive forces, which is achieved by adjusting the $\mathrm{pH}$, or adding salts or low weight polyelectrolytes $[2,5,6]$.

In the copper industry, a preliminary coagulation process generally accompanies the flocculation of clay tailings by neutralizing the surface of the particles with a defined concentration of coagulants. One of the most widely used coagulants in the industry is aluminum sulfate, while the most commonly used polymeric flocculants to destabilize tailings suspensions are high molecular mass anionic polyacrylamides (PAM). The high molecular weight PAM is very effective $[7,8]$.

Normally, flocculation in industrial processes occurs under a shear field to provide good dispersion and contact of particles with flocculants. However, excessive shear can alter the size of the aggregates, generating unfavorable structures for sedimentation [9]. In general, there are two disaggregation mechanisms, surface erosion and large-scale fragmentation [10]. Erosion is the separation of small particles from the surface of the aggregates, while fragmentation refers to the breaking of the aggregates into pieces of comparable size. The rupture mechanism depends on the type of stress to which the suspension is subjected. Such a mechanism can be identified by analysis of particle size distribution. An increase in the number of ultrafine particles is expected when rupture is caused by erosion. An increase in the number of intermediate-size particles is accompanied by a considerable reduction in the size of coarse-sized particles or aggregates when fragmentation predominates.

Suspensions experience various stresses, but the aggregates' strength always depends on the number and strength of the bonds between the particles [11]. This little-explored property of particle aggregates is key information for improving the efficiency of solidliquid separation processes, since it finally determines the structural changes of the aggregates from the feedwell to the underflow of the thickeners from where the pulp is expelled for its final disposition. Operationally, this is of great importance considering that the small disaggregated particles sediment slowly, if at all, affecting the quality of the recovered water and modifying the rheological properties of the thickened pulps.

Considering that the aggregation rate corresponds to an equilibrium between aggregate formation and disaggregation, Gregory et al. [12] proposed the aggregate size as an indicator of aggregate strength for a given shear rate. However, this relationship does not predict aggregates' behavior before increasing shear once it has already been formed. A method that can provide more information is based on calculating the aggregates' strength factor by comparing the size before and after applying an increase in shear [13,14] according to Equation (1).

$$
\text { Strength factor }=\frac{d(2)}{d(1)} \times 100
$$

where $d(1)$ is the volume median aggregate diameter before the increase in shear and $d(2)$ is the size after the increase in shear.

The higher the value of the strength factor, the less prone are flocs to rupture due to increased shear rate and are therefore considered stronger. However, the resistance factor is a subjective parameter since it is dependent on the shear rates chosen by the operator before and after generating the change in the intensity of agitation. This methodology can be complemented by considering the magnitude of the shear rate change, as did Leentvaar and Rebhun [15]. These researchers analyzed the evolution of floc size, gradually increasing the shear of the suspensions. Then, they performed a linearization through the Parker equation [16], as indicated in Equation (2),

$$
\log d=\log C-\gamma \log G
$$


In this case, $d$ is the volume media aggregate diameter, $C$ is the coefficient of resistance, $G$ is the average shear rate, and $\gamma$ is the stability exponent of the aggregate. These researchers evaluated the average aggregate size just before each change in shear rate, which was performed every 5 minutes in a range of $20-120 \mathrm{~s}^{-1}$. This model shows a good fit of the experimental data, and generally, good linearity between the floc size and the shear rate on the logarithmic scale is observed for a number of experimental studies $[17,18]$. The method is simple to implement and requires few experimental tests, although there is some confusion in the literature as to how to interpret the model; some researchers interpret $\log C$ as a resistance parameter and the value of $\gamma$ as the dominant mode of degradation of flocs $[13,15,16,19]$, while another interpretation considers $\gamma$ as a resistance parameter against an increase in shear [20]. Like the strength factor, this model does not provide complete information on the response of a floc to applying different levels of shear rate once it has been formed under established conditions (flocculation time and intensity of agitation). Any increase in the shear rate alters the initial properties of the floc, causing each measurement to be on a structure with different properties, which do not necessarily represent the characteristics of the original floc.

An interesting study was carried out by Blanco et al. [21], who analyzed the evolution of the mean chord size using FBRM after applying a sharp increase in the shear rate. The researchers determined the resistance of the flocs to shear forces by fitting the evolution of the mean chord size to a pseudo-first-order model Equation (3).

$$
y=C_{0}+A \cdot e^{-\frac{t}{T_{d f}}}
$$

$T_{d f}$ was considered a global measure of floc resistance, associating it with a combination of the force of the flocs themselves and the dynamic of the re-flocculation rate without changing the conditions.

The applied model fits well with the experimental data. The resistance parameter has physical coherence since it corresponds to the inverse of the size reduction rate for time. Therefore, a higher value of $\mathrm{T}$ will imply that the flocs reduce their size at a lower speed. However, the relationship between $\mathrm{T}$ and the increased shear rate is unknown. Therefore, this methodology does not predict flocs' behavior when applying a different shear rate.

This work aims to provide a criterion to analyze the resistance of the aggregates for different salinities standardizing the effects of mixing intensity and stirring time. The evolution of the aggregates' size is analyzed by applying different levels of shear; however, all the experiments are carried out on the aggregate's original structure. In general, there are a series of variables that determine the properties of the aggregates; characteristics of the mineral (size and charge density), characteristics of the flocculant (structure, molecular weight, charge density, and concentration), conditions of the medium (salinity and $\mathrm{pH}$ ), shear rate, etc. [22]. This research aims to analyze the effect of salinity on the strength of kaolin aggregates flocculated with a high molecular weight anionic polyelectrolyte. The results may be of practical interest since, generally, the water used in solid-liquid separation processes has a high ionic concentration, particularly for mining plants that use seawater in their operations.

\section{Methodology}

\subsection{Materials}

Kaolin particles were from Ward's Science. Volume weighted particle size distribution (PSD) was obtained using a Microtrac S3500 laser diffraction analyzer (Verder Scientific, Newtown, PA, USA). Its composition was determined by XRD analysis on a Bruker, D8 Advance X-ray diffractometer (Bruker, Billerica, MA, USA) using the Powder Diffraction File of 2020 ICDD (International Center for Diffraction Data) database. The spectra show a majority (over $10 \%$ ) of halite and kaolinite and a minority (1-10\%) of $\mathrm{SiO}_{2}$ (Figure 1). Furthermore, the FTIR spectrum (Figure 2) showed a characteristic kaolin double peak at 3696 and $3654 \mathrm{~cm}^{-1}$. Three absorption bands at 3696, 3654, and $3621 \mathrm{~cm}^{-1}$ reflected the 
high structural order of the samples by the $\mathrm{OH}$ stretching of the hydroxyl groups on the inner surface. There was stretching from Si-O to 1115,1032 , and $1009 \mathrm{~cm}^{-1}$. The Al-O-Si strain appeared at $539 \mathrm{~cm}^{-1}$, the Si-O-Si strain appeared at $471 \mathrm{~cm}^{-1}$, and the Si-O strain appeared at $431 \mathrm{~cm}^{-1}$. As shown in Figure 3, the kaolin particles had a d10 of $1.8 \mu \mathrm{m}$; that is, the portion of particles with sizes smaller than this value is $10 \%$. The flocculant used was the commercial acrylamide SNF704, an anionic acrylate copolymer supplied by SNF-Chile with $98 \%$ purity, prepared as a stock solution of $1 \mathrm{~g} / \mathrm{L}$ in distilled water, and kept refrigerated for a maximum period of 2 weeks. $0.1 \mathrm{~g} / \mathrm{L}$ solutions were prepared daily from the stock solution. These solutions were used in the experimental tests and then discarded $24 \mathrm{~h}$ after their preparation. The salt used was analytical grade $\mathrm{NaCl}$ from Merck (Santiago, Chile).

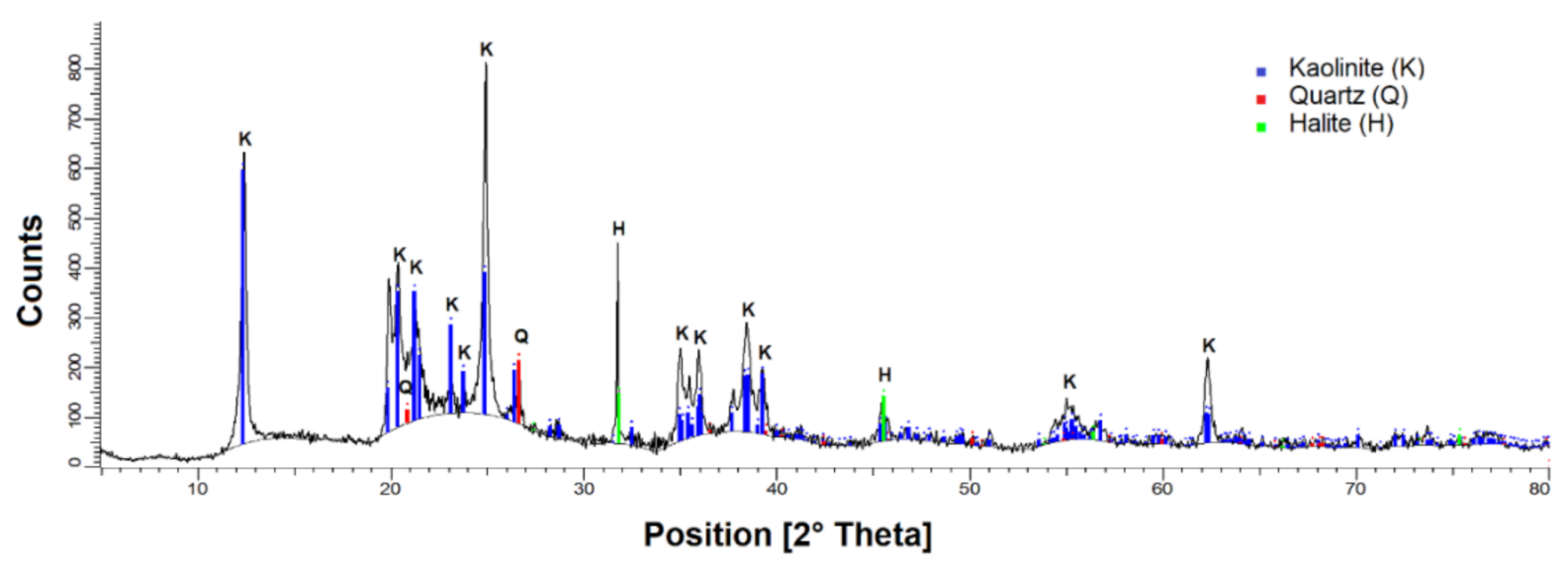

Figure 1. X-ray diffraction spectrum of kaolin particles.

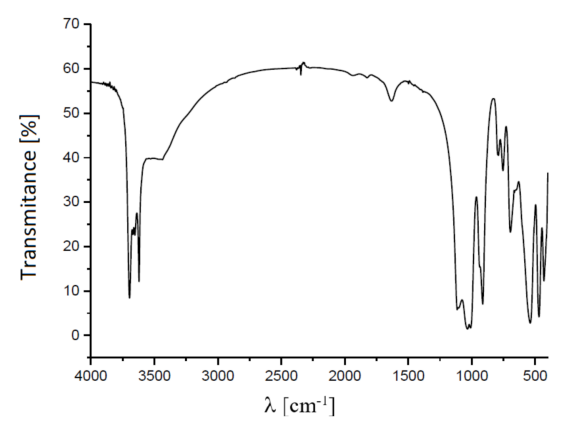

Figure 2. Fourier transform infrared spectroscopy (FTIR) spectrum for kaolin powder.

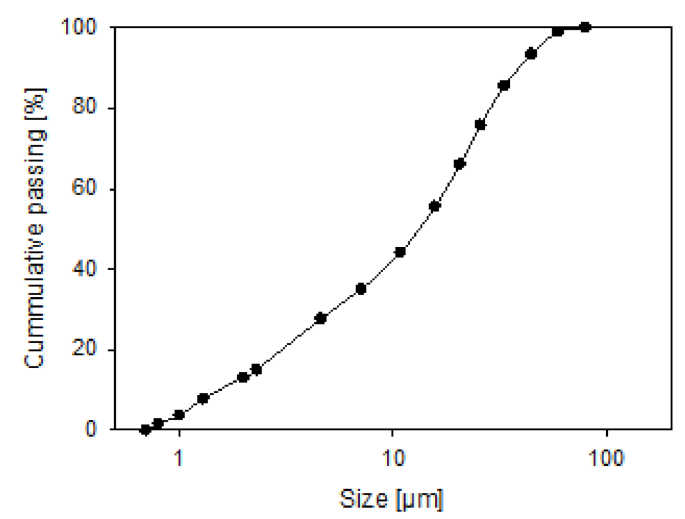

Figure 3. Particle size distribution of a mixture of quartz and kaolin in distilled water at natural $\mathrm{pH}$. Mechanical agitation was maintained overnight. 


\subsection{Aggregate Characterization}

The flocculation of kaolin particles was carried out in a cylindrical container of $1 \mathrm{~L}$ capacity and $100 \mathrm{~mm}$ in diameter, which had an 80-mm diameter turbine impeller at the end of a vertical shaft (4 $\mathrm{mm}$ in diameter) to keep particles suspended. The base of the impeller was placed $20 \mathrm{~mm}$ above the bottom of the container.

The minerals were added to a saline solution of distilled water with a preset salt concentration to give a total mass of $270 \mathrm{~g}$. Then, the flocculant in solution was added at the required dose, ensuring a suspension with a total mass of $300 \mathrm{~g}$ and $4 \%$ by weight of solids. The kaolin pulp was stirred at $600 \mathrm{rpm}\left(\mathrm{G}=1400 \mathrm{~s}^{-1}\right.$ approx) for $60 \mathrm{~min}$ at natural $\mathrm{pH}$ to keep the particles dispersed before flocculation. The stirring was then reduced to $200 \mathrm{rpm}\left(\mathrm{G}=273 \mathrm{~s}^{-1}\right)$, and after $2 \mathrm{~min}$, the flocculant was added at a dose of $40 \mathrm{~g} / \mathrm{t}$. At this stage, the flocculation kinetics were analyzed for $3 \mathrm{~min}$. Then, the mixing intensity was increased to promote flocculation. Five increments were evaluated up to $G=1516 \mathrm{~s}^{-1}$, each for $4 \mathrm{~min}$.

The Focused Beam Reflectance Measurement (FBRM) system (Particle Track E25, Mettler Toledo, OH, USA) was used to measure the aggregate size evolution (Figure 4). The system consists of a processing unit with a $19 \mathrm{~mm}$ diameter probe tip placed vertically in the flocculation vessel $10 \mathrm{~mm}$ above the stirrer and $20 \mathrm{~mm}$ off the rotation axis. The technology is based on light backscattering using a revolving laser beam projected into the sample suspension through a sapphire window (14 $\mathrm{mm}$ in diameter) at the end of the probe. The beam rotates at $2 \mathrm{~m} / \mathrm{s}$, and thus the particles still appear despite the stirring of the sample suspension. The light backscatter time of each particle is multiplied by the scanning speed resulting in a chord length that correlates with the true particle size. A chord length distribution (CLD) of the particles is obtained in real-time in a specified measurement time span. The raw chord length distributions (unweighted) were considered not to lose information on the smallest aggregates, and the squared-weighted chord distributions to not lose information on the largest aggregates. The average size of the aggregates was obtained considering the squared-weighted chord distribution acquired every $2 \mathrm{~s}$.

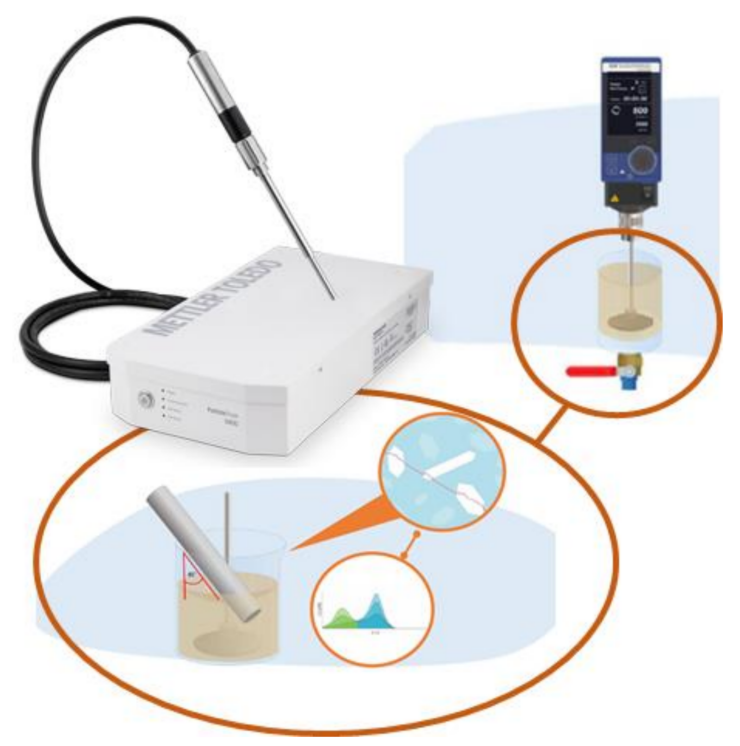

Figure 4. Representation of floc size detection system with FBRM probe.

\subsection{Mean Shear Rate (G)}

The mean shear rate required by the aggregation and breakage kernels is calculated from:

$$
G=\left(\frac{\varepsilon \rho_{s u s}}{\mu_{\text {sus }}}\right)^{\frac{1}{2}}
$$


where $\mu_{\text {sus }}$ is the viscosity ( $\left.4 \mathrm{mPas}\right), \rho_{\text {sus }}$ is the pulp density, and $\varepsilon$ is the average energy dissipation rate:

$$
\varepsilon=\frac{N_{p} N^{3} D^{5}}{V}
$$

$N p$ is the impeller power number ( 0.6 in our case for a plane disk with gentle agitation [2], $N$ is the rotation speed, $D$ and $V$ are, respectively, the diameter of the impeller and the working volume of the impeller vessel. The density of the suspension $\rho_{\text {sus }}$ is calculated from:

$$
\rho_{\text {sus }}=\left(\frac{w}{\rho_{s}}+\frac{1-w}{\rho_{w}}\right)^{-1}
$$

where $w$ is the mass fraction of solids in suspension, and $\rho_{s}$ and $\rho_{w}$ are the density of solid and water, respectively. The parameters are indicated in Table 1.

Table 1. Inputs to calculate the mean shear rate.

\begin{tabular}{ccc}
\hline Parameter & \multicolumn{3}{c}{ Value } \\
\hline$\mu_{\text {sus }}$ & 0.004 & $\mathrm{~kg} /(\mathrm{m} \cdot \mathrm{s})$ \\
\hline$N_{p}$ & 0.6 & \\
\hline$D$ & 0.08 & $\mathrm{~m}$ \\
\hline$W$ & 0.04 & \\
\hline$\rho_{s}$ & 2600 & $\mathrm{~kg} / \mathrm{m}^{3}$ \\
\hline$\rho_{w}$ & 1000 & $\mathrm{~kg} / \mathrm{m}^{3}$ \\
\hline$V$ & 0.25 & $\mathrm{~L}$ \\
\hline
\end{tabular}

\section{Results}

\subsection{Particle Aggregation without Flocculant}

Figure 5 shows the unweighted and square-weighted size distributions for kaolin suspensions in water with various salinities $(0-0.1 \mathrm{M} \mathrm{NaCl})$. The unweighted distributions are more sensitive to changes in the proportion of fine particles, while the squared-weighted distributions are more sensitive to the contribution of particle aggregates. According to the results, the salinity does not affect either type of size distribution. In all cases, the unweighted distribution shows a peak close to 20 microns, while the squared-weighted distribution shows a peak close to 50 microns.
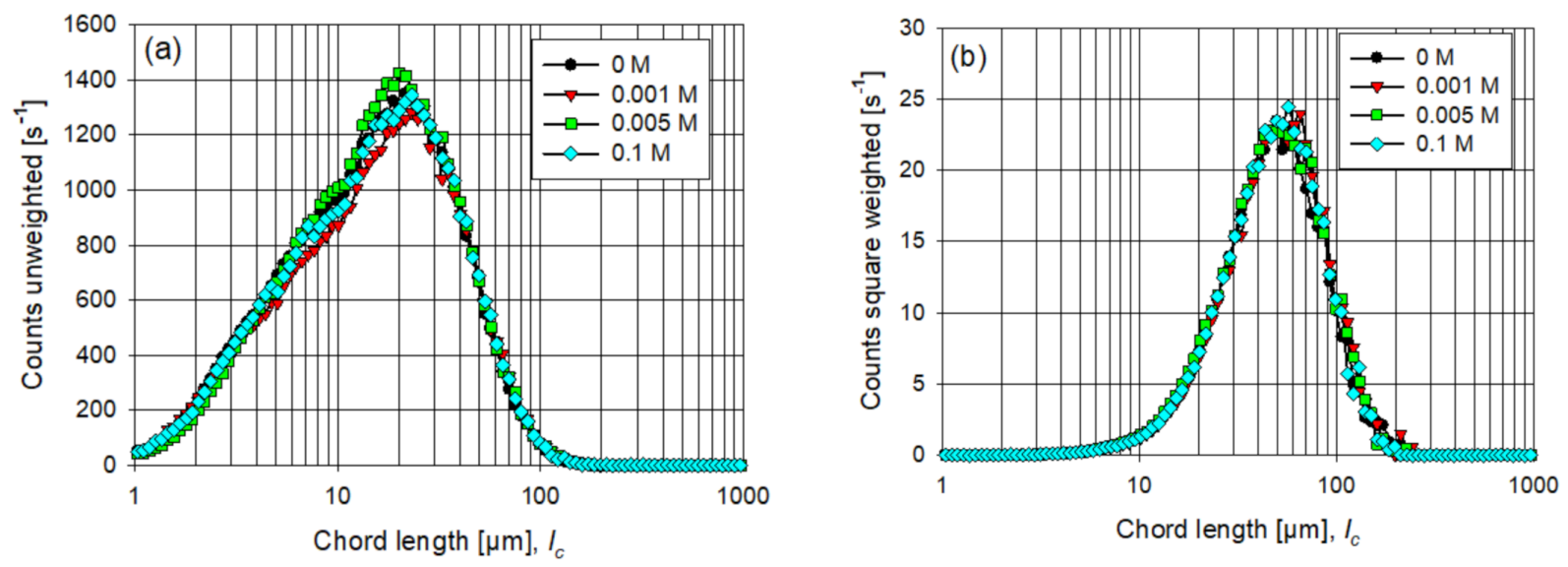

Figure 5. Unweighted (a) and squared-weighted (b) size distribution of kaolin suspension without flocculant at different salinities. 
Previous studies $[23,24]$ establish that the clay's edges have a positive charge at the working $\mathrm{pH}$ (approximately 5), while the faces have a negative charge. In this sense, at low salinity, the electrostatic attraction between edges (E) and faces (F) is promoted, leading to aggregates with an EF configuration. However, in a saline environment, the cations tend to neutralize the attraction between the particles, inhibiting EF-configuration aggregates, but favor forming FF-structure aggregates by attraction by van der Waals forces. None of this is observed under the conditions considered in this study since no significant differences are observed in the aggregates' chord lengths.

\subsection{Aggregation of Flocculated Particles}

Figure 6 shows the evolution of kaolin's average size in solutions with increasing salinity before and after adding the polymer. The flocculant-free suspension has an average chord length of 53 microns (obtained from the quadratic distribution), regardless of the salinity of the system. Upon flocculant addition, instantaneous aggregation occurs until reaching a maximum floc size after a few seconds, as seen in the peaks in Figure 6. Before the peak, the aggregation rate exceeds the floc rupture rate. However, once the peak is reached, the relationship between aggregation and rupture rates is reversed, and the average size decreases over time. This behavior is typical of polymeric bridge flocculation, where the flocculant adheres to several particles simultaneously through tails and loops configurations on the surface of the solid particles. However, the system's hydrodynamics wears down the polymer, causing it to lose its ability to reflocculate the fragmented structures [25].

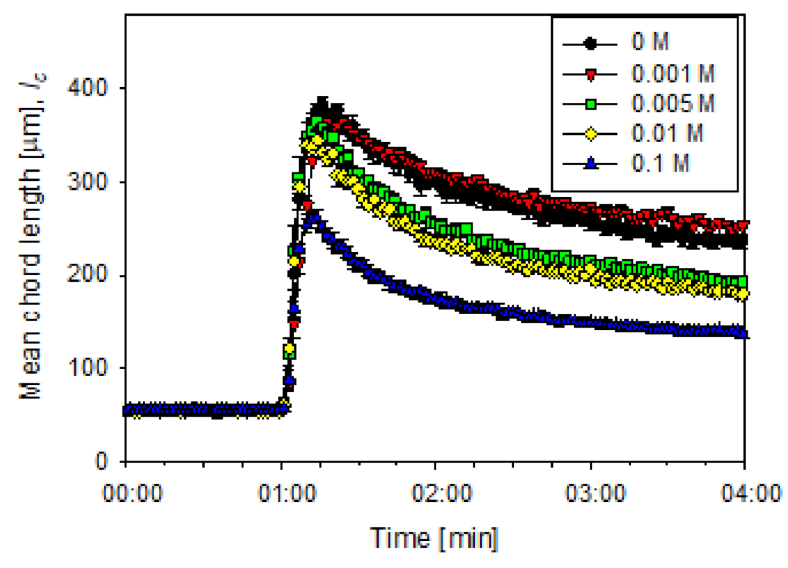

Figure 6. Evolution of the average size of aggregates of kaolin particles (chord length) before and after the addition of flocculant.

Unlike the particle system without flocculant, the presence of salt critically affects the flocculation process. Analysis of the flocculation kinetics after 3 min from the addition of the polymer reveals that salt's addition in low concentration $(0.001 \mathrm{M} \mathrm{NaCl})$ causes an increase in the flocs' average size from 238 to $251 \mu \mathrm{m}$. However, a higher salt concentration decreases the mean floc size, reaching $139 \mu \mathrm{m}$ at a concentration of $0.1 \mathrm{M}$.

The unweighted chord length distribution (Figure 7a) shows that the peak is close to 100 microns in distilled water, while in the squared-weighted distribution (Figure $7 \mathrm{~b}$ ), the peak is close to 110 microns. A small salt $(0.001 \mathrm{M} \mathrm{NaCl})$ addition caused both distribution curves to shift to slightly larger floc sizes. While the height of the unweighted distribution peak decreases (from $400 \mathrm{~s}^{-1}$ to $300 \mathrm{~s}^{-1}$ ), the square-weighted peak increases (from $150 \mathrm{~s}^{-1}$ to $160 \mathrm{~s}^{-1}$ ), indicating that as the number of small aggregates decreases, the number of large massive aggregates increases. These results are expected, because cations promote the flocculant chains' adsorption through cationic bridge bonds with the mineral surface, thus enhancing flocculation [26]. On the other hand, the results show that an increase in salinity $(>0.001 \mathrm{M} \mathrm{NaCl})$ severely inhibits flocculation. Figure 7a indicates that the number of small particles increases, and their size decreases $(<100 \mu \mathrm{m})$ with salt concentration. 
Simultaneously, Figure $7 \mathrm{~b}$ shows that the number of large aggregates decreases. In $0.1 \mathrm{M}$ $\mathrm{NaCl}$, the unweighted distribution peak is located at $70 \mu \mathrm{m}$ with a height of $800 \mathrm{~s}^{-1}$, while the squared-weighted distribution peak is at $120 \mu \mathrm{m}$ with $90 \mathrm{~s}^{-1}$.
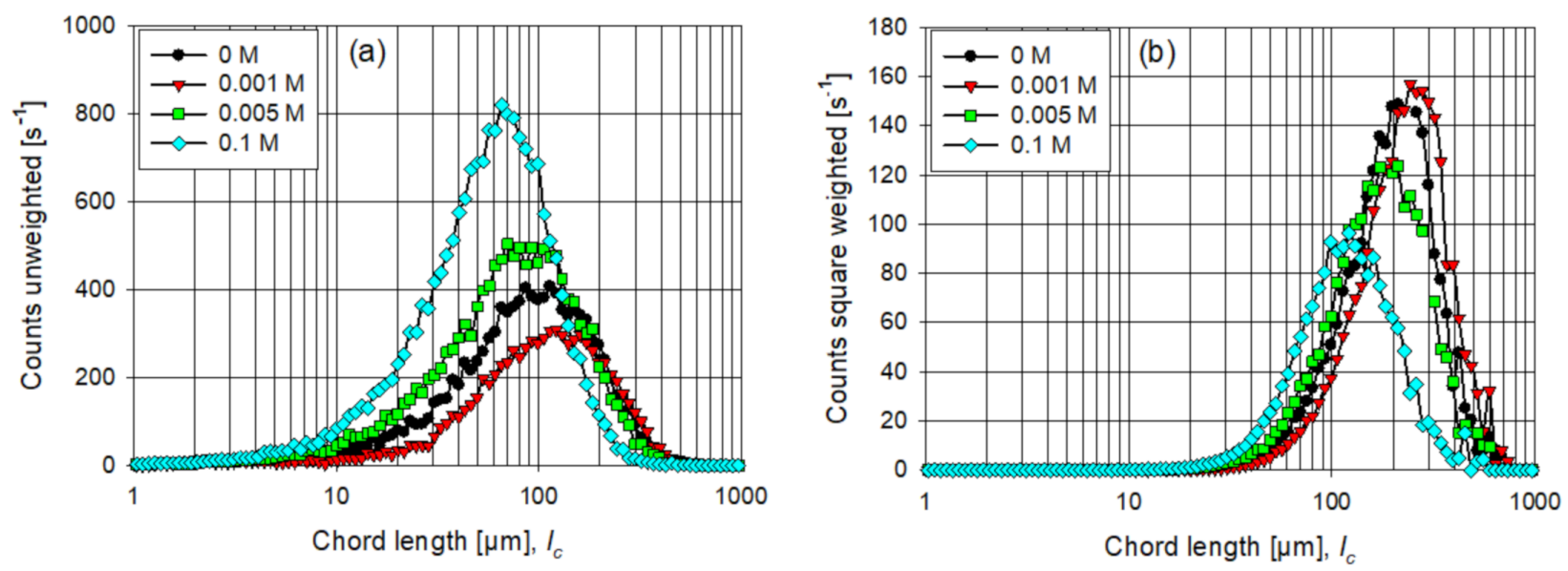

Figure 7. Unweighted (a) and squared-weighted (b) size distribution of kaolin suspensions for different salinities after three minutes of flocculation.

The non-monotonic effect of salinity on kaolin pulp flocculation was observed by Jeldres et al. [27]. They suggest that the structure and size of the aggregates is a response to the competition of two mechanisms triggered by salinity: (i) coiling of the flocculant due to the neutralization of the charge of its anionic functional groups (acrylate group); and (ii) improving the adsorption of the polymer by cationic bridges between the active sites in the flocculant and on the surface of the particles. $\mathrm{Na}^{+}$cations are located between the anionic monomers of the flocculant (acrylate) and the anionic groups on the clay's surface (aluminol groups). The results suggest that at low salt concentrations, adsorption improves, while the reduction of the polymer volume is too insignificant to lower the flocculation efficiency. However, higher salinity leads to a significant reduction in the volume of the flocculant, reducing its ability to form polymeric bridges.

\subsection{Aggregate Shear Fragmentation}

After three minutes of flocculation, the system is disturbed by increasing the shear rate over the $G=273 \mathrm{~s}^{-1}$ initially used in the flocculation tests. The increments are from 0 to $1516 \mathrm{~s}^{-1}$. Figure 8 shows the chord length distributions after $20 \mathrm{~s}$ in the following cases: (i) without disturbance (Figure 8a,b), the mixing intensity is kept at $G=273 \mathrm{~s}^{-1}$; (ii) $\mathrm{G}=229 \mathrm{~s}^{-1}$ increment (Figure 8c,d); (iii) $\mathrm{G}=1516 \mathrm{~s}^{-1}$ (Figure 8e,f). The effect of salinity on the size distribution is the same as in Section 3.2; that is, the effect is not monotonous since a small addition of salt favors agglomeration $(0.001 \mathrm{M} \mathrm{NaCl})$, while considerable increases in salinity lead to smaller aggregates. However, these trends become less apparent when the mixing intensity is high. The more aggressive the agitation, the less observable are the effects caused by the increase in salinity, reaching the case where significant differences in behavior are not appreciated, as occurs when the agitation is increased by $\mathrm{G}=1516 \mathrm{~s}^{-1}$ (Figure 8e,f). Under these extreme hydrodynamic conditions, the fragmentation of aggregates is practically complete, disintegrating the aggregates until particles of a size very close to that of the primary particles is obtained. 

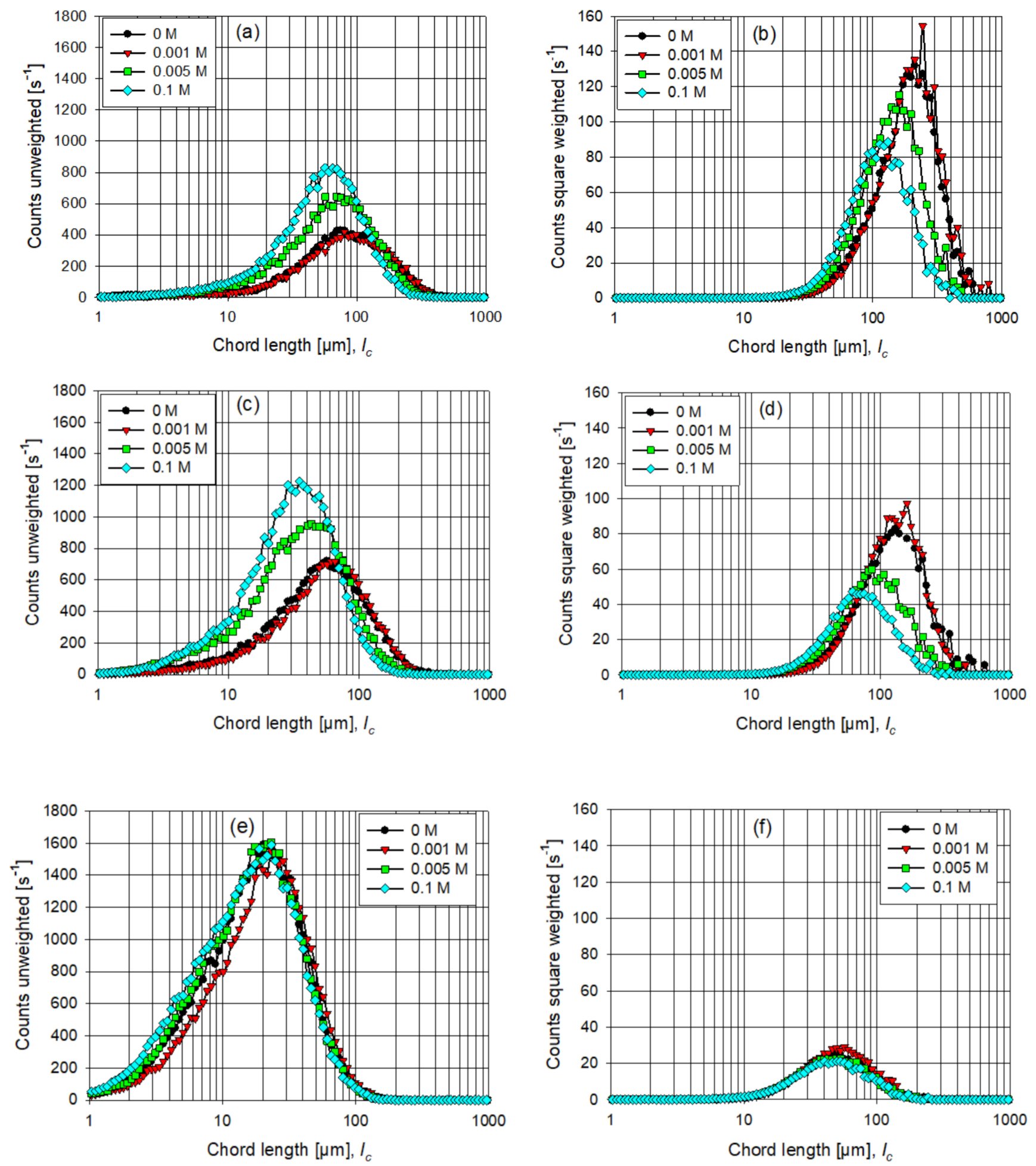

Figure 8. Unweighted (left column) and squared-weighted (right column) kaolin cord length distributions in saline solutions $(\mathrm{NaCl})$. The distributions were measured $20 \mathrm{~s}$ after increasing the initial agitation of the flocculation process. The first row, $(\mathbf{a}, \mathbf{b})$, corresponds to the base case at $G=273 \mathrm{~s}^{-1}$, the second row, $(\mathbf{c}, \mathrm{d})$, at $\mathrm{G}=502 \mathrm{~s}^{-1}\left(\mathrm{G}=229 \mathrm{~s}^{-1}\right.$ increment), and the third row, (e,f), at $\mathrm{G}=1789 \mathrm{~s}^{-1}\left(\mathrm{G}=1516 \mathrm{~s}^{-1}\right.$ increment).

An increase in agitation leads to increased unweighted distributions and a decrease in the squared-weighted distributions. The shape of the curves suggests that the fragmentation of the aggregates mainly causes the size reduction. Although it is not ruled out that erosion may exist, this phenomenon is characterized by the release of fine particles, 
which is why a new peak of primary particles would be expected, generating bimodal distributions; however, the FBRM probe did not capture this characteristic.

\subsection{Aggregate Strength}

A representative parameter of the resistance of the aggregates is obtained from the evolution curves of the average floc size at different salinities against changes in the mixing intensity (Figure 9). Here, it is reiterated that the interest is to evaluate the impact of salinity on the resistance of the aggregates of a kaolin suspension (4 wt\%) flocculated with polyacrylamide at a dose of $40 \mathrm{~g} / \mathrm{t}$. It is also reiterated that the flocculation time considered is $3 \mathrm{~min}$ from the time the flocculant is added and that the mixing intensity is $273 \mathrm{~s}^{-1}$. These conditions are expected to affect the strength of the aggregates, which is what this work seeks to determine. After three minutes, the agitation increases, and the flocculation kinetics are studied for a further four minutes.
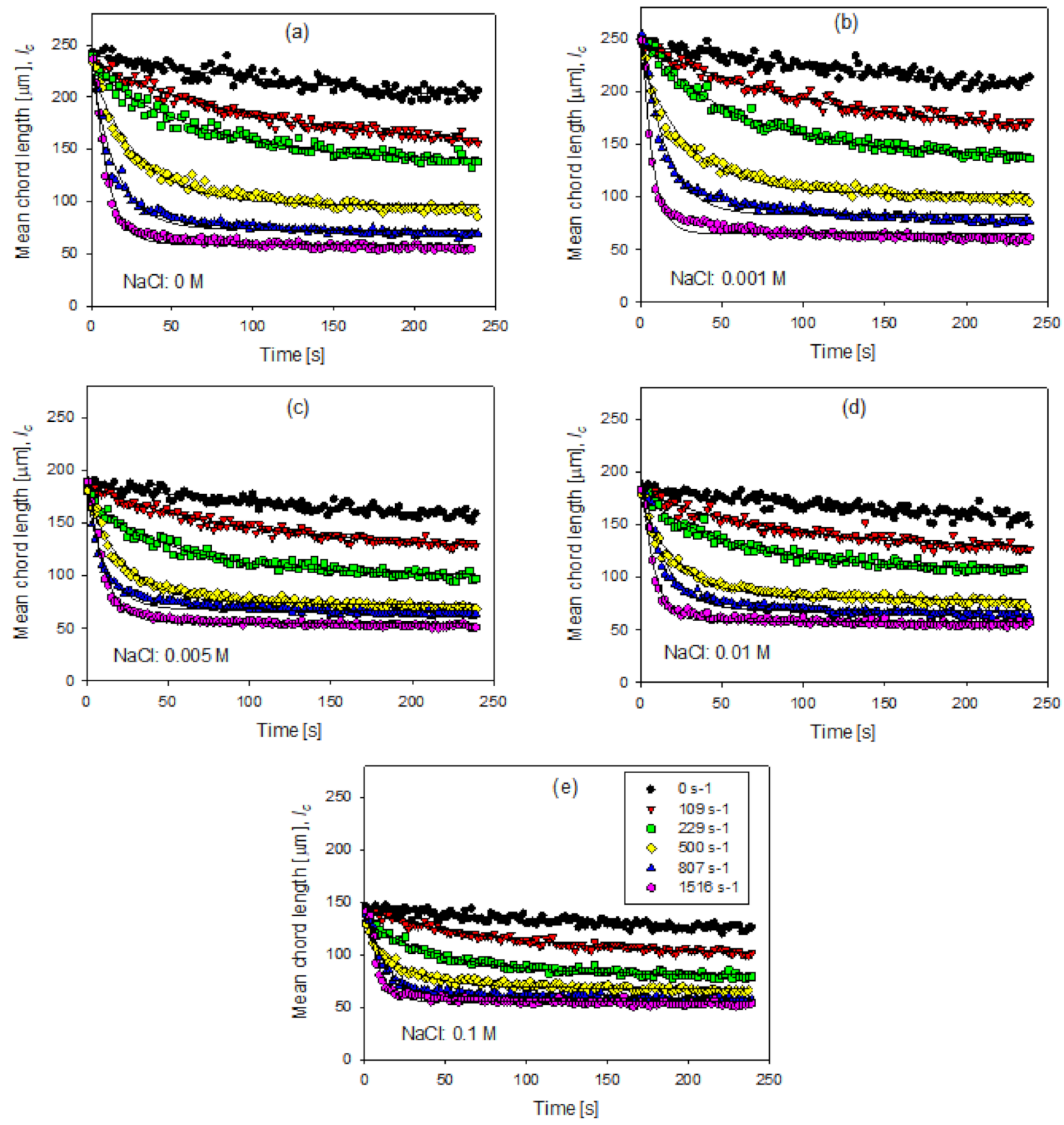

Figure 9. Evolution of the average size of kaolin aggregates in saline solutions $(\mathrm{NaCl})$ after incrementing the shear rate. Experimental data (points) and curve fitting to Equation (7) (continuous lines). 
The evolution of the aggregate size for a specific increment in agitation can be represented by a pseudo-first-order model Equation (7) [21]:

$$
y(t)=y_{0}-A\left(1-e^{-b t}\right)
$$

where $y(t)$ is the average size of the aggregates as a function of time, $y_{0}$ is the average size of the aggregates just before the increment in agitation, $b$ is the decay constant of the aggregate size, and $A$ represents the amplitude of the size reduction of the aggregates, as shown in Equation (8).

$$
A=y_{0}-y_{\infty}
$$

where $y_{\infty}$ corresponds to the size reached at a shear during an infinite time.

Table 2 shows the effect of salinity and the increase in the shear rate on the amplitude of the aggregate size reduction (A). For each difference in shear, it is observed that the relationship between $\mathrm{A}$ and salinity is not monotonous. There is an increase in the value at a low salt concentration $(0.001 \mathrm{M})$ compared with the suspension without salt. Later, it decreases gradually with the increase in salinity, presenting a behavior directly associated with the size of the floc formed. By subjecting the floc to shear for an infinite time, the size that it would reach presents a decreasing relationship with the applied rate.

Table 2. Amplitude of the size reduction of the aggregates (A) at different salinities and shear rate increases.

\begin{tabular}{cccccc}
\hline \multirow{2}{*}{ Delta $\mathbf{~} \mathbf{s}^{-\mathbf{1}} \mathbf{)}$} & \multicolumn{5}{c}{ Amplitude of the Size Reduction of the Aggregates (A) } \\
\cline { 2 - 6 } & $\mathbf{0 ~ M}$ & $\mathbf{0 . 0 0 1} \mathbf{M}$ & $\mathbf{0 . 0 0 5} \mathbf{M}$ & $\mathbf{0 . 0 1} \mathbf{~ M}$ & $\mathbf{0 . 1} \mathbf{~ M}$ \\
\hline 109 & 81.7 & 86.5 & 64.7 & 56.5 & 41.7 \\
\hline 229 & 97.1 & 112.1 & 85.9 & 76.2 & 57.9 \\
\hline 500 & 141.4 & 14.7 & 108.8 & 103.9 & 71.1 \\
\hline 807 & 164.9 & 169.0 & 125.6 & 115.7 & 80.2 \\
\hline 1516 & 180.2 & 186.8 & 138.6 & 125.5 & 84.5 \\
\hline
\end{tabular}

For its part, the constant decay $b$, which is related to the rate at which the flocs break, presents a direct relationship with the applied shear (Table 3) since a greater disturbance leads to the flocs breaking faster. However, a relationship with salinity is not observed.

Table 3. Decay constants of the size of the aggregates (b) at different salinities and shear rate increases.

\begin{tabular}{cccccc}
\hline \multirow{2}{*}{ Delta $\left.\mathbf{~ G ~} \mathbf{s}^{-\mathbf{1}}\right)$} & \multicolumn{5}{c}{ Decay Constant of the Size of the Aggregates (b) } \\
\cline { 2 - 6 } & $\mathbf{0 ~ M}$ & $\mathbf{0 . 0 0 1} \mathbf{M}$ & $\mathbf{0 . 0 0 5} \mathbf{M}$ & $\mathbf{0 . 0 1} \mathbf{~ M}$ & $\mathbf{0 . 1} \mathbf{~ M}$ \\
\hline 109 & 0.0114 & 0.0115 & 0.0133 & 0.0129 & 0.0096 \\
\hline 229 & 0.0168 & 0.0176 & 0.0246 & 0.0172 & 0.0253 \\
\hline 500 & 0.0322 & 0.0428 & 0.0581 & 0.0396 & 0.0421 \\
\hline 807 & 0.0590 & 0.0613 & 0.0797 & 0.0677 & 0.0729 \\
\hline 1516 & 0.0669 & 0.1260 & 0.0872 & 0.1419 & 0.1041 \\
\hline
\end{tabular}

It is possible to estimate the maximum aggregate rupture at an infinite time for each increment in shear rate $(\Delta G)$; for this, Equation (9) is used:

$$
R_{\max }=100 \times A /\left(y_{0}-d_{0}\right)
$$

with $R_{\max }$ being the maximum aggregate rupture percent and $d_{0}$ the average size of the primary particles. Calculated $R_{\max }$ for the aggregates in Figure 9 are shown in Figure 10. 


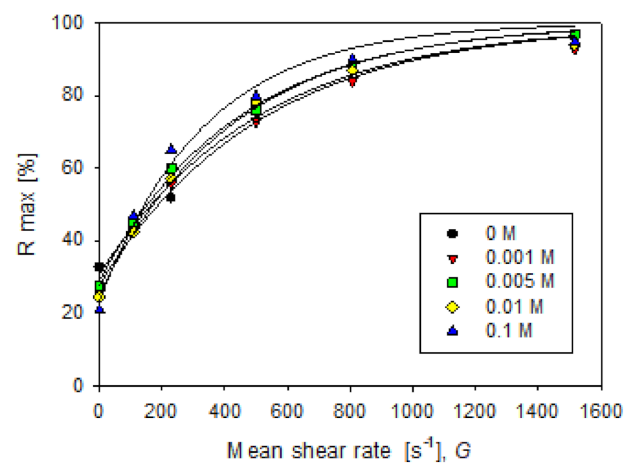

Figure 10. Percentage of maximum rupture (at an infinite time) of aggregates of kaolin in saline solutions $(\mathrm{NaCl})$ for each increase in agitation from the base of $\mathrm{G}=273 \mathrm{~s}^{-1}$.

The data in Figure 10 can be represented by Equation (10), which allows us to estimate the rupture degree as a function of shear rate increments explicitly at different salt concentrations,

$$
R_{\max }=R_{\max , 0}+U\left(1-e^{-x / R}\right)
$$

where $x$ is the agitation increment $(\Delta \mathrm{G}), R_{\max , 0}$ is the maximum aggregate rupture percent when there is no disturbance of agitation (constant mean shear rate of $273 \mathrm{~s}^{-1}$ ). $U$ is the difference between the maximum rupture at an infinite shear rate $(\Delta G \rightarrow \infty)$ and the rupture degree at the base agitation of $273 \mathrm{~s}^{-1}(\Delta \mathrm{G}=0), R$ is the characteristic shear rate, used as an indicator of the aggregate resistance. To correctly interpret the parameters obtained after fitting Equation (10), the restriction in Equation (11) is added, which corresponds to the system's response when the mixing intensity is very high; in mathematical terms, the limit is $\Delta G \rightarrow \infty$. In this case, the aggregate's total rupture is presumed, giving rise to a suspension of dispersed primary particles, such as before adding the flocculant.

$$
R_{\max , 0}+U=100 \%
$$

The strength of the aggregates is related to their ability to resist rupture when the system is subjected to hydrodynamic forces, in this case, generated by the mixing of the pulp itself. The more resistant the aggregates, the less they break due to agitation, which has significant practical consequences, for example, in the design of feedwells for thickeners in solid-liquid separation operations [28,29].

From Equation (10), the characteristic shear rate $R$ is required to obtain $R_{\max }-R_{\max , 0}=$ $63.2 \%$. In this work, we suggest that this be a criterion to analyze the resistance of the aggregates $(R)$ to different salinities. This simple criterion offers advantages over current methods of estimating the strength of aggregates by shear induction; for example, the measurement time is standardized to estimate the change in aggregate size after the agitation period is incremented. Considering the aggregate rupture at an infinite time (estimated through Equation (9)), the uncertainty of using different agitation times is discarded. On the other hand, the aggregates change their structures over time $[9,30]$; therefore, the criterion proposed is based on studying the resistance at a fixed flocculation time ( $3 \mathrm{~min}$ ) and shear rate $\left(\mathrm{G}=273 \mathrm{~s}^{-1}\right)$. If the aggregates are formed under some other conditions, their strength may differ. The fitting parameters obtained from Equation (10) to the data in Figure 10 are shown in Table 4. $R_{\max , 0}$ tends to decrease in value with increasing salinity. This trend would be influenced by the initial size and strength of the aggregate, considering that a larger structure is more prone to breakage and takes longer to achieve a balance between the rate of aggregation and fragmentation. On the other hand, $\mathrm{U}$ reflects the difference between the maximum rupture at an infinite shear rate and at the rupture degree at the base shear rate $(\Delta \mathrm{G}=0)$ depending directly on $R_{\max , 0}$ when considering the restriction proposed in Equation (11). 
Table 4. Parameters of Equation (10) for the best representation of the data in Figure 10.

\begin{tabular}{ccccc}
\hline Salt, $\mathbf{M}$ & $\boldsymbol{R}_{\boldsymbol{m a x}, \mathbf{0}}[\%]$ & $\boldsymbol{U}[\%]$ & $\boldsymbol{R}\left[\boldsymbol{s}^{-\mathbf{1}}\right]$ & $\boldsymbol{R}^{\mathbf{2}}$ \\
\hline 0 & 32.66 & 67.34 & 530 & 0.9903 \\
\hline 0.001 & 25.72 & 74.28 & 492 & 0.9910 \\
\hline 0.005 & 27.66 & 72.34 & 428 & 0.9964 \\
\hline 0.01 & 24.39 & 75.61 & 422 & 0.9943 \\
\hline 0.1 & 20.76 & 79.24 & 320 & 0.9822 \\
\hline
\end{tabular}

Salinity alters the flocculation process by modifying the interaction forces between the particles. Figure 11 shows the effect of $\mathrm{NaCl}$ concentration on the resistance of kaolin flocs in terms of the aggregate resistance $R$ obtained from Equation (10). The result is interesting, considering that a monotonic relationship is obtained between the salinity of the system and the strength acquired by the particle networks. The maximum resistance is achieved when the aggregates are formed in a salt-free environment, with $R=530 \mathrm{~s}^{-1}$. This value gradually decreases, in the form of exponential decay, with increasing salt concentration, reaching $R=320 \mathrm{~s}^{-1}$ at a concentration of $0.1 \mathrm{M}$. This reduction in floc resistance can be explained based on structural changes prompted by salinity.

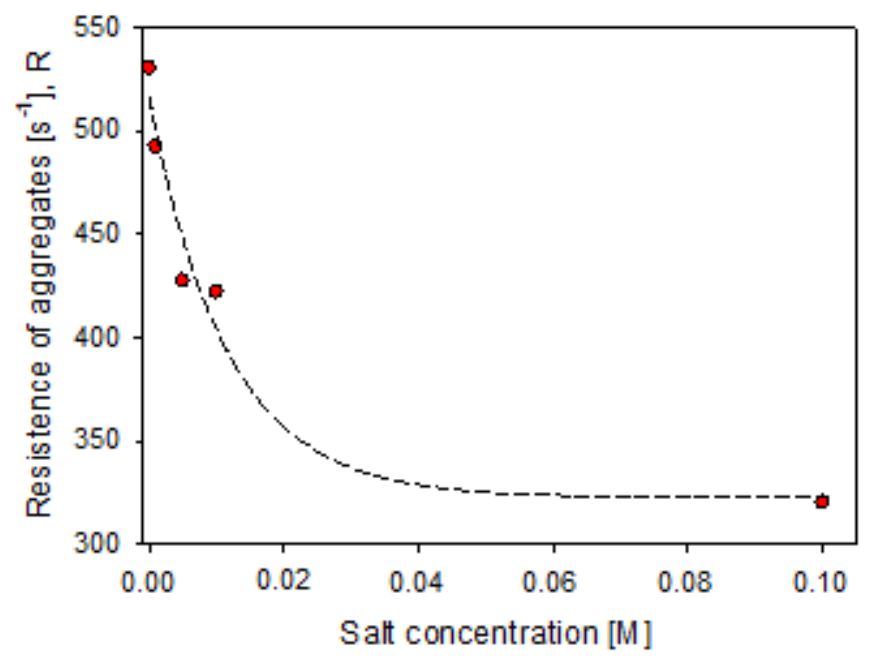

Figure 11. Effect of salinity on the resistance of kaolin aggregates $(R)$.

Several studies have shown that salinity causes significant changes in the conformation of the flocculant and particle-particle and flocculant-particle interactions. Recently, Quezada et al. [31] observed through a molecular dynamics approach that the proportion of train configurations increases with the ionic strength of the solution, which implies that a greater proportion of functional groups of the flocculant remain adhered to the surface of the same particle, leaving fewer monomers of the chain available for the formation of polymeric bridges; therefore, the floc is formed by a smaller quantity of particles. At the same time, the anionic flocculants undergo coiling due to the lower electrostatic repulsion of their functional groups. Additionally, the strength of the aggregates can be influenced by the initial state of aggregation of the primary particles before the addition of the polymer. At the $\mathrm{pH}$ of the suspension (approximately pH 5.5), the kaolin particles in distilled water form aggregates through electrostatic attraction between their cationic edges and their anionic faces (card-house structure), while when the ion concentration increases, an electrostatic shielding of the mineral surface reduces the amount of EF bonds and increases the FF-type organizations.

The methodology presented in this work standardizes a method to quantify the resistance of aggregates by shear induction, obtaining a parameter that does not depend on 
the hydrodynamic conditions chosen to establish the disturbances, unlike models available in the literature, which, although they work adequately within the experimental conditions carried out for their validation, are not necessarily extrapolated and comparable in different systems. An example is seen in Table 5, where the resistance parameters are obtained by the method proposed by Blanco et al. [21] and François et al. [13]. The parameters obtained by Blanco et al. are dependent on the shear rate chosen for the disturbance. For the conditions of our system, only the resistance trend for salinity is captured when the mean shear rate was $G=229 \mathrm{~s}^{-1}$. Higher shear rates $\left(G=807 \mathrm{~s}^{-1}\right.$ and $\left.G=1516 \mathrm{~s}^{-1}\right)$ excessively fragment the structures, and it is not possible to know their resistance. What happens with the proposal of François et al. is similar, where the methodology must be tuned according to each particular system, obtaining results that depend on the chosen shear rate (Table 5).

Table 5. Effect of salinity and shearing on the resistance of flocculated kaolin aggregates in a saline medium. Resistance is obtained through different methodologies.

\begin{tabular}{|c|c|c|c|c|c|c|c|}
\hline \multirow{2}{*}{ Salinity } & \multicolumn{3}{|c|}{ Blanco et al. [21] } & \multicolumn{3}{|c|}{ François et al. [13] } & \multirow{2}{*}{$\begin{array}{c}\mathrm{R}\left[\mathrm{s}^{-1}\right] \text { from } \\
\text { Equation (10) }\end{array}$} \\
\hline & $\mathrm{G}=229 \mathrm{~s}^{-1}$ & $\mathrm{G}=807 \mathrm{~s}^{-1}$ & $\begin{array}{c}\mathrm{G}=1516 \\
\mathrm{~s}^{-1}\end{array}$ & $\mathrm{G}=229 \mathrm{~s}^{-1}$ & $\mathrm{G}=807 \mathrm{~s}^{-1}$ & $\begin{array}{c}\mathrm{G}=1516 \\
\mathrm{~s}^{-1}\end{array}$ & \\
\hline $0 \mathrm{M}$ & 53.6 & 14.8 & 14.8 & 0.71 & 0.34 & 0.27 & 530 \\
\hline $0.001 \mathrm{M}$ & 56.6 & 16.3 & 7.9 & 0.71 & 0.36 & 0.28 & 492 \\
\hline $0.005 \mathrm{M}$ & 40.8 & 16.1 & 12.1 & 0.71 & 0.40 & 0.31 & 428 \\
\hline $0.01 \mathrm{M}$ & 58.7 & 17.5 & 7.1 & 0.71 & 0.42 & 0.35 & 422 \\
\hline $0.1 \mathrm{M}$ & 39.8 & 13.8 & 9.6 & 0.69 & 0.47 & 0.41 & 320 \\
\hline
\end{tabular}

\section{Conclusions}

This research aims to standardize a method that provides the resistance of aggregates by shear induction, obtaining a parameter that does not depend on the hydrodynamic conditions chosen to establish the disturbances. The evolution of the aggregates' size is analyzed by applying different levels of shear; however, all the experiments are carried out on the aggregate's original structure. The salinity study is a tool to validate the proposed method to quantify the strength of kaolin aggregates flocculated with a high molecular weight anionic polyelectrolyte.

The monotonic relationship between the shear rate increments $(\Delta G)$ and the final size of the aggregates is used for a more quantitative estimate of the resistance of the target aggregates since a pseudo-first-order model can describe this relationship.

Analysis of the flocculation kinetics after $3 \mathrm{~min}$ from the addition of the polymer reveals that the addition of salt at a low concentration $(0.001 \mathrm{M} \mathrm{NaCl})$ causes an increase in the flocs' average size from 238 to $251 \mu \mathrm{m}$. However, a higher salt concentration decreases the mean floc size, reaching $139 \mu \mathrm{m}$ at a concentration of $0.1 \mathrm{M}$. On the other hand, the results show a monotonous relationship between resistance and salinity, where an increase in salt concentration leads to a reduction in floc resistance to shear. Salinity significantly alters flocculation mechanisms; therefore, this relationship can be explained by (i) structural changes (aggregation modes) of kaolin prompted by salinity, (ii) changes in the conformation of the anionic flocculants that undergo coiling due to the lower electrostatic repulsion of their functional groups, and (iii) changes in flocculant-particle interactions, where the adsorption of the anionic polymer on kaolin surfaces increases in a saline environment. 
Author Contributions: Conceptualization, M.J. and R.I.J.; methodology, P.R. and W.H.L.; formal analysis, M.J., P.G.T., P.R. and R.I.J.; investigation, M.J.; data curation, L.A. and E.G.; writingoriginal draft preparation, M.J. and R.I.J.; writing—review and editing, P.R., L.A., E.G., P.G.T.; project administration, R.I.J.; funding acquisition, R.I.J. All authors have read and agreed to the published version of the manuscript.

Funding: This research was funded by CRHIAM Project ANID/FONDAP/15130015.

Data Availability Statement: The data presented in this study are available on request from authors M. Jeldres and R.I. Jeldres.

Acknowledgments: Ricardo I. Jeldres and Pedro G. Toledo thank CRHIAM Project ANID/FONDAP / 15130015. Matías Jeldres acknowledges the infrastructure and support of the Programa de Doctorado en Ingeniería de Procesos de Minerales of the Universidad de Antofagasta. Pedro Robles thanks the Pontificia Universidad Católica de Valparaíso for the support provided.

Conflicts of Interest: The authors declare no conflict of interest.

\section{References}

1. Berlin, A.A.; Kislenko, V.N. Kinetic models of suspension flocculation by polymers. Colloids Surf. A Physicochem. Eng. Asp. 1995, 104, 67-72. [CrossRef]

2. Bremmell, K.E.; Jameson, G.J.; Biggs, S. Polyelectrolyte adsorption at the solid/liquid interface interaction forces and stability. Colloids Surf. A Physicochem. Eng. Asp. 1998, 139, 199-211. [CrossRef]

3. Biggs, S.; Habgood, M.; Jameson, G.J.; Yan, Y. Aggregate structures formed via a bridging flocculation mechanism. Chem. Eng. J. 2000, 80, 13-22. [CrossRef]

4. Vajihinejad, V.; Gumfekar, S.P.; Bazoubandi, B.; Rostami Najafabadi, Z.; Soares, J.B.P. Water soluble polymer flocculants: Synthesis, characterization, and performance assessment. Macromol. Mater. Eng. 2019, 304, 1800526. [CrossRef]

5. Hubbe, M.A.; Nanko, H.; McNeal, M.R. Retention aid polymer interactions with cellulosic surfaces and suspensions: A review. BioResources 2009, 4, 850-906. [CrossRef]

6. Cadotte, M.; Tellier, M.E.; Blanco, A.; Fuente, E.; Van De Ven, T.G.M.; Paris, J. Floculation, retention and drainage in papermaking: A comparative study of polymeric additives. Can. J. Chem. Eng. 2007, 85, 240-248. [CrossRef]

7. Nabzar, L.; Pefferkorn, E.; Varoqui, R. Polyacrylamide-sodium kaolinite interactions: Flocculation behavior of polymer clay suspensions. J. Colloid Interface Sci. 1984, 102, 380-388. [CrossRef]

8. Lee, L.T.; Rahbari, R.; Lecourtier, J.; Chauveteau, G. Adsorption of polyacrylamides on the different faces of kaolinites. J. Colloid Interface Sci. 1991, 147, 351-357. [CrossRef]

9. Leiva, W.H.; Fawell, P.D.; Goñi, C.; Toro, N.; Jeldres, R.I. Temporal evolution of the structure of tailings aggregates flocculated in seawater. Miner. Eng. 2021, 160, 106708. [CrossRef]

10. Rasteiro, M.G.; Garcia, F.A.P.; Ferreira, P.; Blanco, A.; Negro, C.; Antunes, E. Evaluation of flocs resistance and reflocculation capacity using the LDS technique. Powder Technol. 2008, 183, 231-238. [CrossRef]

11. Bache, D.H.; Johnson, C.; McGilligan, J.F.; Rasool, E. A conceptual view of floc structure in the sweep floc domain. In Water Science and Technology; Elsevier Science Ltd: Amsterdam, The Netherlands, 1997; Volume 36, pp. 49-56.

12. Gregory, J. Monitoring floc formation and breakage. Water Sci. Technol. 2004, 50, 163-170. [CrossRef]

13. François, R.J. Strength of aluminium hydroxide flocs. Water Res. 1987, 21, 1023-1030. [CrossRef]

14. Fitzpatrick, C.S.B.; Fradin, E.; Gregory, J. Temperature effects on flocculation, using different coagulants. Water Sci. Technol. 2004, 50, 171-175. [CrossRef]

15. Leentvaar, J.; Rebhun, M. Strength of ferric hydroxide flocs. Water Res. 1983, 17, 895-902. [CrossRef]

16. Parker, D.S.; Kaufman, W.J.; Jenkins, D. Floc breakup in turbulent flocculation processes. J. Sanit. Eng. Div. 1972, 98, 79-99. [CrossRef]

17. Biggs, C.A.; Lant, P.A. Activated sludge flocculation: On-line determination of floc size and the effect of shear. Water Res. 2000, 34, 2542-2550. [CrossRef]

18. Bache, D.H.; Rasool, E.; Moffat, D.; McGilligan, F.J. On the strength and character of alumino-humic flocs. Water Sci. Technol. 1999, 40, 81-88. [CrossRef]

19. Bache, D.H. Floc rupture and turbulence: A framework for analysis. Chem. Eng. Sci. 2004, 59, 2521-2534. [CrossRef]

20. Jarvis, P.; Jefferson, B.; Gregory, J.; Parsons, S.A. A review of floc strength and breakage. Water Res. 2005, 39, 3121-3137. [CrossRef]

21. Blanco, A.; Fuente, E.; Negro, C.; Tijero, J. Flocculation monitoring: Focused beam reflectance measurement as a measurement tool. Can. J. Chem. Eng. 2008, 80, 1-7. [CrossRef]

22. Antunes, E.; Garcia, F.A.P.; Ferreira, P.; Blanco, A.; Negro, C.; Rasteiro, M.G. Effect of water cationic content on flocculation, flocs resistance and reflocculation capacity of PCC induced by polyelectrolytes. Ind. Eng. Chem. Res. 2008, 47, 6006-6013. [CrossRef]

23. Lagaly, G.H. van Olphen: An Introduction to Clay Colloid Chemistry, 2nd ed; John Wiley \& Sons: New York, NY, USA; London, UK; Sydney, Australia; Toronto, CN, Canada, 1977. 318 Seiten, Preis: £ 15.-, \$ 25.-. Ber. der Bunsenges. für Phys. Chem. 1978, 82, 236-237. [CrossRef] 
24. Rand, B.; Melton, I.E. Particle interactions in aqueous kaolinite suspensions. I. Effect of $\mathrm{pH}$ and electrolyte upon the mode of particle interaction in homoionic sodium kaolinite suspensions. J. Colloid Interface Sci. 1977, 60, 308-320. [CrossRef]

25. Jeldres, R.I.; Fawell, P.D.; Florio, B.J. Population balance modelling to describe the particle aggregation process: A review. Powder Technol. 2018, 326, 190-207. [CrossRef]

26. Quezada, G.R.; Jeldres, M.; Toro, N.; Robles, P.; Toledo, P.G.; Jeldres, R.I. Understanding the flocculation mechanism of quartz and kaolinite with polyacrylamide in seawater: A molecular dynamics approach. Colloids Surf. A Physicochem. Eng. Asp. 2021, 608,125576 . [CrossRef]

27. Jeldres, R.I.; Piceros, E.C.; Leiva, W.H.; Toledo, P.G.; Herrera, N. Viscoelasticity and yielding properties of flocculated kaolinite sediments in saline water. Colloids Surf. A Physicochem. Eng. Asp. 2017, 529, 1009-1015. [CrossRef]

28. Nguyen, T.; Farrow, J.; Smith, J.; Fawell, P. Design and Development of A Novel Thickener Feedwell Using Computational Fluid Dynamics. J. South. Afr. Inst. Min. Metall. 2012, 112, 105-119.

29. Fawell, P.D.; Nguyen, T.V.; Solnordal, C.B.; Stephens, D.W. Enhancing gravity thickener feedwell design and operation for optimal flocculation through the application of computational fluid dynamics. Miner. Process. Extr. Metall. Rev. 2019, 1-15. [CrossRef]

30. Selomulya, C.; Bushell, G.; Amal, R.; Waite, T.D. Understanding the role of restructuring in flocculation: The application of a population balance model. Chem. Eng. Sci. 2003, 58, 327-338. [CrossRef]

31. Quezada, G.R.; Jeldres, R.I.; Fawell, P.D.; Toledo, P.G. Use of molecular dynamics to study the conformation of an anionic polyelectrolyte in saline medium and its adsorption on a quartz surface. Miner. Eng. 2018, 129, 102-105. [CrossRef] 